\title{
Automated Vehicles, On-Demand Mobility, and Environmental Impacts
}

\author{
Jeffery B. Greenblatt ${ }^{1} \cdot$ Susan Shaheen ${ }^{2}$
}

Published online: 21 July 2015

(C) Springer International Publishing AG 2015

\begin{abstract}
We review the history, current developments, projected future trends and environmental impacts of automated vehicles (AVs) and on-demand mobility, and explore potential synergies. Many automobile manufacturers and Google plan to release AVs between 2017 and 2020, with potential benefits including increased safety, more efficient road use, increased driver productivity and energy savings. Estimates of AV energy use and greenhouse gas (GHG) emissions range from an $\sim 80 \%$ or greater decrease to a threefold increase; however, we argue that net decreases are likely. On-demand mobility services exist in many cities around the world, with advances in mobile technology increasing their popularity. On-demand mobility can provide numerous transportation, land use, and environmental and social benefits, and users tend to decrease both vehicle ownership and annual vehicle distances traveled. Combining on-demand mobility and AVs may amplify adoption of both, and further lower energy use and GHG emissions through the use of small, efficient shared AVs.
\end{abstract}

Keywords Automated vehicles · On-demand mobility · Energy use $\cdot$ Greenhouse gas · Self-driving $\cdot$ Driverless

This article is part of the Topical Collection on Transportation.

Jeffery B. Greenblatt

JBGreenblatt@lbl.gov

1 Energy Analysis and Environmental Impacts Division, Lawrence Berkeley National Laboratory, Berkeley, USA

2 Transportation Sustainability Research Center, University of California, Berkeley, USA

\section{Introduction}

Two emerging trends in personal transportation-automated vehicles (AVs, also known as self-driving or driverless vehicles) and on-demand mobility (also known as carsharing, ridesharing, ridesourcing or e-hail services) - may provide important alternatives to conventional transportation (private vehicles and public transit) and may even dramatically disrupt the status quo in a few years' time, if accepted widely. Both are enabled by recently available technology, though AVs are arguably more dependent on cutting-edge technology, since they essentially replace human decision making with computer algorithms. While it is "early days" for AVs, several analysts have projected possibly transformative changes to personal transport, with potentially nearly all vehicles becoming autonomous by mid-century. According to Frost and Sullivan, membership in carsharing is forecast at 4.4 million in North America and 5.5 million in Europe by 2016 [1], although these projections may be too optimistic. Current North American membership is approximately 1.5 million [2] and total vehicles is 22,018 . Total worldwide membership in October 2014 was estimated at 4.8 million and $\sim 104,000$ vehicles [3].

In addition to their potential importance to the future of mobility, both trends may also have large, mainly beneficial, energy use and environmental impacts, so we explore each trend in detail, as well as look into the consequences of combining them together.

\section{Automated Vehicles \\ Background, History}

AVs, broadly defined, are conveyances to move passengers or freight without human intervention. AV research has 
existed for decades, and many people already travel on semiautonomous aircraft and trains [4]. AV technology development began in 1977 in Japan [5], and it has subsequently included Germany, Italy, the European Union, and the USA [5-8]. From 2004 to 2007, the US Defense Advanced Research Projects Agency sponsored Grand Challenge races with large prizes [9]. Carnegie Mellon University [10], Environmental Research Institute of Michigan [11], and SRI International [12] provided a foundation for current activities by major auto manufacturers, Tesla Motors and Google, all of who are developing AV technologies [13-19]. Moreover, four US states (Nevada, California, Florida, and Michigan) and Washington, DC, have passed legislation allowing testing of AVs, with 13 more contemplating similar laws, and Nevada has provided a pathway to commercialization via its certification process [19-23].

The National Highway Transportation Safety Administration [24] has defined five levels of AV functionality, ranging from no $\mathrm{AV}$ features (level 0) to full automation without the need for a human driver (level 4). Levels 1 and 2 include some AV capability, while level 3 achieves limited automation, defined as enabling "the driver to cede full control of all safety-critical functions under certain traffic or environmental conditions" but expecting the driver "to be available for occasional control" with adequate warning. IHS Automotive [25] expanded these definitions to include level 5 (full automation without driver controls). For a summary, see Table 1. Most manufacturers pursuing AV technology are focused on partial automation (levels 1 to 3), but several manufacturers have offered concept vehicles with full automation. Tesla and Google have announced plans to release level 4 vehicles by 2017 and 2020, respectively [25].

The technology to enable automation, particularly at levels 3 and above, is extremely sophisticated and, currently, very expensive ( US\$150,000; [19]). Multiple cameras and/or roof-mounted LIDAR to rapidly scan the environment in every direction, high-performance computational hardware, state-of-the-art image processing and decision-making algorithms, high-speed Internet connectivity, and up-to-the-minute, highly detailed maps are needed.

Claimed AV benefits include increased safety, more efficient road use, increased driver productivity, and energy savings [19, 26-30]. Shifting driving from human to machine is potentially disruptive both technologically and socially, opening new possibilities like dispatching, parking, and refueling vehicles without human intervention and providing mobility for people currently unable to drive [27-29]. AV proliferation would dramatically depart from "business as usual" and has significant economic, energy security, policy, and research implications for transportation, energy, and the environment. As such, it is important for energy modelers, environmental advocates, economists and policy analysts to examine the potential of AVs thoughtfully.

\section{Current Developments and Projected Trends}

All manufacturers that have announced plans for AVs already offer or plan to release vehicles with some automated features by 2017 , and level 3 systems are expected by 2017 to 2020 . As mentioned above, Google has announced plans to release a level 4 system by 2017 [19], and Tesla has announced its intention by 2020 [31]. Researchers disagree on when AVs will become generally available. IHS Automotive [25] projects level 3 functionality by 2020, level 4 by 2025 , and level 5 by 2030 , with AVs reaching $9 \%$ of sales in 2035 and $90 \%$ of the vehicle fleet by 2055. Navigant Consulting [32] was even more optimistic, expecting $75 \%$ of light-duty vehicle sales to be automated by 2035 , whereas the Insurance Information Institute [33] claims that all cars may be automated by 2030. KPMG [34] conducted a focus group study and found that across a range of demographics and driving preferences, Americans are more willing than not to embrace self-driving cars. Others are more cautious; Gomes [35] reported that among 500 experts attending a recent $\mathrm{AV}$ conference, half did not expect to see level 4 AVs until 2030, with $20 \%$ putting the date at 2040 , and $10 \%$ "never" expecting

Table 1 Vehicle automation level definitions

Automation level Description

Level $0 \quad$ No automation

Level 1 Autonomy of one primary control function, e.g., adaptive cruise control, self-parking, lane-keep assist, or autonomous braking

Level 2 Autonomy of two or more primary control functions "designed to work in unison to relieve the driver of control of those functions"

Level 3 Limited self-driving; driver may "cede full control of all safety-critical functions under certain traffic or environmental conditions," but it is "expected to be available for occasional control" with adequate warning

Level $4 \quad$ Full self-driving; driver "is not expected to be available for control at any time during the trip" (includes unoccupied vehicles)

Level $5 \quad$ Full self-driving without human controls

Sources: ([59]; IHS [25]) 
them. ${ }^{1}$ Cabanatuan [36] similarly expressed skepticism among some researchers. However, Troppe [37] believes that AVs will be "inevitable within the 21st century," and the Eno Center [38] considered scenarios ranging from 10 to $90 \%$ fleet penetration of AVs in an unspecified year but presumably after 2030.

Concurrent with this projected expansion, analysts project a tremendous reduction in the cost of $\mathrm{AV}$ technology. When introduced around 2025, AV technology is projected to have a price premium of US\$7000 to $\$ 10,000$ [25], a more than tenfold drop from today's estimated prototype costs. Mass adoption of $\mathrm{AV}$ technology will require a price premium of $\sim$ US\$1000, according to IHS Automotive [25]; this level would reduce the cost of AV technology to that of typical add-ons (sunroof, leather seats, etc.).

Before AVs can take off, however, a number of policy issues would need to be addressed including legality of testing and operation, operator certification, liability, communication and interface standards, security, and data access and custody [19, 25].

\section{Research on Environmental Sustainability}

While many environmental factors are worth considering including: impacts on air quality, water consumption, land use change, and biodiversity, we limit our environmental impact assessment in this article to energy and greenhouse gas (GHG) emissions. However, it is worth mentioning the potentially large impacts on urban land use through increased road use and decreased parking requirements that AVs may engender. Work by Chester et al. [39] indicates that parking currently adds from 1.3 to 25 grams of carbon dioxide equivalent/ passenger-kilometer $(\mathrm{km})$ to total lifecycle GHG emissions of vehicle transport, depending on the scenario, and from 24 to $89 \%$ to sulfur dioxide and $10 \mu \mathrm{m}$ particulate matter emissions; with a large decrease in parking requirements, a substantial fraction of these emissions could be eliminated.

The impacts on human health would lie primarily in reduced accidents, though if AVs enable greater use of battery electric vehicles (BEVs) or hydrogen fuel cell vehicles (HFCVs), improvements in air quality would also be significant because these technologies emit no ozone-forming precursors (nitrogen oxides, volatile organic compounds) or particulate matter that can cause respiratory illnesses. The National Highway Traffic Safety Administration (NHTSA) [40] found that $93 \%$ of crashes between 2005 and 2007 were human-caused, while the New York Department of Motor Vehicles [41] found a lower human attribution rate (78\%). If AVs could eliminate all human causes of crashes, accident rates could fall by $\sim 80$ to $90 \%$. Studies have estimated the

\footnotetext{
${ }^{1}$ The actual question asked was whether the expert "would trust a fully robotic car to take their children to school" [35].
}

economic benefits of crash reduction ( $\sim$ US $\$ 280$ billion/year in 2010 or US $\$ 1232 /$ year/vehicle) [40, 42]. Together with decreases in insurance, traffic congestion, and parking costs, AV benefits could amount to between US\$2960 and US\$3900/year/vehicle [38]. Thus, once the cost of AV technology falls to $\sim \mathrm{US} \$ 10,000, \mathrm{AV}$ technology could more than pay for itself over typical vehicle loan periods.

Researchers estimate that AVs could reduce energy use up to $\sim 80 \%$ from platooning, efficient traffic flow and parking, safety-induced light-weighting, and automated ridesharing [27-29, 38, 43]. In addition, Greenblatt and Saxena [44] have found that small, shared electric AVs in combination with a future low-carbon electricity grid could reduce per-mile $(\mathrm{km})$ GHG emissions by $\sim 90 \%$ compared with today's vehicles; for further discussion, see section titled "Potential Automated Vehicle and Carsharing Synergies."

On the other hand, researchers speculate that vehicle miles (or kilometers) traveled (VMT/VKT) of AVs could increase dramatically due to a combination of factors including: increased use by those currently unable to drive, increased numbers of trips (both occupied and unoccupied), a shift away from public transit, additional VMT/VKT due to self-parking and self-fueling, and longer commutes [27-29, 38, 43]. Larger, more luxurious vehicles or higher average speeds would also increase energy use. Brown et al. [28] estimate that VMT/VKT could approximately double and overall energy use increase threefold under these circumstances.

Overall, we do not think that dramatic increases in energy use are likely, however, because the trends outlined above would likely occur together with energy savings. Assuming that some AV designs increase a vehicle's energy consumption, while others decrease it, the combination of the two trends operating together on future roadways is more likely to reduce net energy consumption because of the system-wide energy savings from AVs (e.g., platooning, efficient traffic flow). The potential energy savings estimated from AVs are much larger than the estimated worst-case growth in energy use and other factors - such as increasing fuel prices and road congestion, and indications that younger people are driving less [45] would also tend to lower energy use. Moreover, the increased use of electric vehicles could significantly lower energy use and GHG emissions relative to gasoline. However, if the overall change does increase energy consumption, the increase would likely be modest due to these ameliorating effects. This conclusion would hold even if the additional advantages of small, shared electric AVs do not materialize.

While such changes are important and potentially dramatic, it will take some time before the penetrations of $\mathrm{AVs}$ grow to levels substantial enough to influence average transportation sector energy use, with an average vehicle lifetime of 13 to 15 years [46]; even if $50 \%$ of sales were AVs starting in 2030, it would take at least 25 to 30 years for most vehicles to be replaced. 


\section{On-Demand Mobility}

On-demand mobility is the use of shared vehicles accessed ondemand. Travelers typically reserve a vehicle or ride via a smartphone application ("app") shortly before the trip is made. On-demand mobility fits into the broader and burgeoning area of mobility and the sharing economy, which is the shared use of a vehicle, bicycle, or other transportation mode on an as-needed basis. The sharing economy is a developing phenomenon around renting and borrowing goods and services rather than owning them. This sharing can take place among peers (peerto-peer) or through businesses (business-to-consumer). With further advances in technology and a developing societal paradigm in which access is valued differently than ownership, shared-use mobility services could continue to grow substantially in use and impact in the coming years.

\section{Background, History}

On-demand mobility typically takes the forms of carsharing (short-term auto use), ridesharing (carpooling/vanpooling), ridesourcing services (also known as transportation network companies, such as uberX, Lyft, and Sidecar), and e-hail services. Each form is described in the subsequent sections.

\section{Carsharing}

Carsharing is short-term access to a shared automobile. North American carsharing first launched in Canada in 1994. This was followed by the emergence of numerous programs throughout the USA, starting in 1998, and throughout Canada. As of July 2014, there were 45 operators in the Americas (roundtrip and one-way) including the USA, Canada, Mexico, and Brazil [47]. Individuals gain the benefits of private vehicle use without the costs and responsibilities of ownership, as they only pay a monthly and/or per-use fee. Individuals typically access vehicles by joining an organization that maintains a fleet deployed in lots located within neighborhoods, public transit stations, employment centers, and colleges/universities. Service models can include roundtrip carsharing (vehicle is returned to its origin), oneway station-based (vehicle is returned to different designated carsharing location), and one-way free-floating (vehicle can be returned anywhere within a geo-fenced area).

\section{Ridesharing}

Ridesharing, also known as carpooling and vanpooling, in its traditional form involves travelers that share a vehicle for tripmaking from a common origin, destination or both, and reducing the number of vehicles on the road. Ridesharing in North America began in the 1940 s as a way to preserve resources for the war effort and reemerged in the 1970s in response to the oil crises. Telephone-based and computerized ridematching emerged in the 1980s and 1990s in an attempt to garner a critical mass of users. Since 2004, technologyenabled ridematching has built upon past attempts to encourage carpooling, partnering with public agencies and large employers and offering incentives to try carpooling [48].

\section{Ridesourcing/Transportation Network Companies (TNCs)}

Ridesourcing services (also known as transportation network companies or TNCs) provide prearranged and on-demand transportation services for compensation, connecting drivers of personal vehicles with passengers. Smartphone apps are used for booking, ratings (both drivers and passengers), and electronic, cashless payment. Ridesourcing launched in San Francisco, CA, in summer 2012, and it has since spread rapidly across the USA and globally, meeting both support and resistance.

\section{E-hail}

E-hail services are a type of for-hire vehicle service, which use a smartphone app to electronically hail a taxi on-demand. While most taxis can be reserved or dispatched through street hailing or dispatching through a phone operator, e-hail apps have been developed as ridesourcing has simultaneously proliferated in the on-demand mobility space. Similar to ridesourcing services, e-hail apps facilitate real-time matching of passengers to drivers and electronic payment.

\section{Current Developments and Projected Trends}

On-demand mobility is undergoing several key developments, using advances in mobile technology to increase the popularity of vehicle sharing for tripmaking.

Recently, ridesourcing companies have released new services that enable riders to share and split the costs of a fare, also known as "ridesplitting." Lyft Line, Sidecar Shared Rides, and uberPOOL aim to group passengers with incidental routes into carpools. Ridesplitting has since grown to three other regions in the USA and is reported to be approximately $50 \%$ of the ridesourcing market in the Bay Area, at the time of this writing.

Furthermore, in November 2014, Lyft released Driver Destination, which enables drivers to pick up passengers along their personal trip routes, for instance, when they are traveling to and from work. In February 2015, Sidecar launched Sidecar Deliveries, which groups passenger trips with same-day deliveries of packages. Such products can facilitate more shared trips, higher vehicle occupancies, and reduced travel costs and provide first-mile and last-mile connectivity to public transit, along those routes.

Both public agencies and private firms have attempted to increase commuter carpooling through various innovations 
since the 1970s. With the advent of Internet-enabled smartphones, new forms of ridesharing are being deployed. "Flexible carpooling" is a more formalized version of slugging that designates formal meeting places for travelers to carpool without advance contact. Finally, the growth of mobile telecommunications has enabled online ridesharing marketplaces, such as Carma Carpooling, where users can arrange rides on-demand or with minimal advanced notice using a smartphone.

Since late 2014, there has been a rise in the application of e-hail services in taxi fleets, particularly in major metropolitan areas using predominantly third-party dispatch apps, such as Flywheel and Curb (formerly Taxi Magic). Increasingly, taxi and limousine regulatory agencies, such as in Chicago, Los Angeles, New York City, and Washington, DC, are developing e-hail pilot programs and mandating e-hail services. In addition, many states and regions throughout the country are adopting legislation to enable ridesourcing/TNC companies to operate (e.g., [49]).

\section{Energy and Environmental Impacts of On-Demand Mobility}

An increasing body of empirical evidence indicates that ondemand mobility can provide numerous transportation, land use, environmental and social benefits. While impact studies on roundtrip carsharing are fairly extensive, the impacts of ridesharing and the newer service models of ridesourcing, ridesplitting, and e-hail services are less studied and understood.

One of the most notable effects of roundtrip carsharing is reduced vehicle ownership. Each carsharing vehicle removes 9 to 13 vehicles (postponed and sold) from the road [50]. Most of this shift in auto ownership is from single households becoming carless, followed by two car households becoming one-car households. The most current studies and member survey results released by the USA and Canadian carsharing organizations show that 15 to $32 \%$ of carsharing members sold their personal vehicles, and between 25 and $71 \%$ of members avoided an auto purchase because of carsharing. A research study by Martin and Shaheen [50] documented that $25 \%$ of members sold a vehicle and $25 \%$ of members postponed a vehicle purchase due to carsharing across a sample of approximately 9500 participants. Additionally, reductions in auto ownership are commonly associated with increased walking, carpooling, and bicycling modal shifts as well as reduced parking demand and VMT/VKT. Twelve to $54 \%$ of carsharing participants in North America walk more often. Studies differ on whether or not carsharing increases or decreases public transit ridership. Studies of six individual locations across North America found that between 13.5 and $54 \%$ take public transit more frequently [51]. Martin and Shaheen [50] found that more carsharing users increased their overall public transit and nonmotorized modal use (including bus, rail, walking, bicycling and carpooling) than decreased it. VMT/VKT is reduced from $27 \%$ (observed impact, based on vehicles sold) to $43 \%$ (full impact, based on vehicles sold and postponed purchases combined) based on the before-and-after mean driving distance [50]. Along with reduced VMT/VKT and vehicle ownership, carsharing also contributes to lower GHG emissions. The mean observed impact was a reduction of 0.58 metric tons of GHG/ year per household and a full impact decline of 0.84 metric tons of GHG/year per household [50] or a 34 to $41 \%$ reduction of GHG emissions per year for one household (mean and full impact, respectively) [52]. Finally, carsharing provides other beneficial societal impacts, such as the increased mobility, afforded by one-way service models and vehicle access by college students and low-income households.

Ridesharing can provide transportation, infrastructure, and environmental benefits, although the exact magnitude of these impacts is not well understood. Individually, ridesharing participants benefit from shared travel costs, travel-time savings from high occupancy vehicle lanes, reduced commute stress, and often preferential parking and other incentives.

A recent study of TNC/ridesourcing users in San Francisco, CA [53], asked respondents for key trip data including the following: trip purpose, origin/destination, and wait times. Thirtynine percent stated that they would have taken a taxi, or $24 \%$ a bus, if ridesourcing were unavailable. Four percent named a public transit station as their origin or destination, suggesting ridesourcing can serve as a first-last-mile trip to and from public transit. Finally, the study found that ridesourcing wait times tended to be substantially shorter than taxi hail and dispatch wait times. Occupancy levels for ridesourcing vehicles averaged 1.8 passengers in contrast to 1.1 passengers for taxis in the matched pair analysis. This study did not examine e-hail taxi services, as they were not widely deployed at the time of the survey. This study did not examine e-hail taxi services, as they were not widely deployed at the time of the survey.

\section{Potential Automated Vehicle and Carsharing Synergies}

AVs have the potential to complement on-demand mobility services, such as carsharing. As discussed in "Automated Vehicles", analysts estimate that by 2020, several major automakers will have developed and released level 3 (limited selfdriving) AVs, with some companies targeting level 4 (full automation) AVs by this time. Even level 3 automation could positively impact the carsharing industry; possible synergies include AVs that drive up to carsharing users (reducing time needed to access a carsharing vehicle), self-parking, and selfrefueling/recharging. With augmented safety features and limited self-driving ability, the inclusion of level $3 \mathrm{AVs}$ into a carsharing fleet could decrease an operator's overall insurance costs, which could translate to cost savings for users. One vision for $\mathrm{AVs}$ is that they provide first- and last-mile 
connectivity to public transit and fill service gaps in the transportation network in the future. Level 4 or 5 automation would further enhance carsharing capability and attractiveness.

Given that the synergy between AVs and shared mobility is still emerging, literature in this area remains sparse. Fagnant and Kockelman [54] developed a trip generation and distribution model, asserting that shared autonomous vehicles (SAVs) have the potential to mitigate the environmental impacts of private auto travel. Given the empirical evidence of carsharing's known impacts on reducing parking requirements, ownership, VMT/VKT, and GHGs, SAVs have the capability of furthering these impacts. SAVs have the advantage of overcoming major existing carsharing barriers, particularly a user's need to travel to carsharing kiosks to access available vehicles. As the study relied on a trip generation and distribution model with a number of assumptions, more research is needed in developing and analyzing real-world applications of AVs in shared mobility.

Greenblatt and Saxena [44] point to other potentially important synergies between AVs and shared vehicles. In addition to being economically more attractive to users than private vehicles, shared vehicles will travel many times further annually than privately owned vehicles, perhaps approaching or even exceeding that of taxis, which can range from $\sim 35,000$ to $\sim 90,000 \mathrm{mi}(\sim 56,000$ to $\sim 145,000 \mathrm{~km})[55-58]$. An important consequence of high annual VMT/VKT is that energy costs will tend to exceed (financed) capital costs, creating a strong economic incentive toward highly efficient vehicles, including BEVs and HFCVs whose life-cycle fuel GHG emissions may also be significantly lower than that of hydrocarbon fuels [44]. This combination makes SAVs not only more attractive economically but also better for the environment. Moreover, the ability to deploy such vehicles according to passenger occupancy needs for each trip could further lower energy consumption and hence GHG emissions. Greenblatt and Saxena [44] found that by relying on small vehicles for the $87 \%$ of US trips that are taken with one or two people [59], and appropriately sized vehicles for higher-occupancy trips, fleet average energy consumption could drop by almost a factor of two. In combination with the higher inherent efficiency of BEVs and lower GHG intensity of electricity relative to gasoline, SAV life-cycle GHG emissions per mile or kilometers could fall by roughly $90 \%$ relative to today's average passenger vehicle. For short trips, BEVs with limited battery capacity and hence driving range could also be employed. Combined, these features would likely make SAVs cheaper than owning a conventional vehicle, but with almost all of their advantages plus the convenience of AVs and large GHG reductions.

\section{Discussion and Conclusions}

It is entirely conceivable that $\mathrm{AVs}$ will become an emergent phenomenon by 2020 , an accepted technology by the 2030 s, and come to dominate personal transportation by 2050 , much as mobile phones have come to dominate personal telecommunications. Moreover, on-demand mobility as enabled by smartphone apps and changing generational expectations could become much more widespread by the 2020 s and grow to occupy a sizable (though probably not majority) share of personal transportation by 2050 .

If AVs become ubiquitous, then SAVs could probably also become a major public transportation mode facilitating accessibility among a wide range of sociodemographic groups, land uses, and those who cannot drive. SAVs would include the benefits outlined above of high efficiency, small size, affordability, and very low GHG emissions, although private AVs would probably continue to exist as an important consumer preference. People will become comfortable with the idea of vehicles driving themselves, while passengers perform other tasks such as texting, talking, watching $\mathrm{TV}$, or reading; vehicles may even evolve among wealthier users to become a type of "mobile home," offering workspace, dining, recreation, or sleeping functions while in transit, though with possible environmental downsides from their much larger size.

In such a future, current trends will hardly apply, as average vehicle ownership, VMT/VKT per person, vehicle occupancy, vehicle size, and commute lengths will depart strongly from historical observations. Energy analysts, economists, transportation planners, policymakers, and social theorists will have to "watch this space" carefully to prevent their projections from becoming inaccurate or (worse) irrelevant. However, chances are good that these technologies will, in aggregate, offer greater energy and environmental benefits to conventional vehicles, taking some pressure off of policy makers and planners who have typically seen the personal mobility sector as difficult to decarbonize.

Acknowledgments We thank Mikhail Chester (Arizona State University) for giving us the opportunity to contribute a manuscript to this special issue, and Greg Dibb (Nissan Research Center) and Bill Morrow (LBNL) for providing comments on the manuscript. Nelson Chan (Transportation Sustainability Research Center, UC Berkeley) provided assistance in reviewing the shared mobility and AV literature for this chapter.

\section{Compliance with Ethics Guidelines}

Conflict of Interest J. B. Greenblatt and S. Shaheen declare that they have no conflict of interest.

Human and Animal Rights and Informed Consent This article does not contain any studies with human or animal subjects performed by any of the authors. 


\section{References}

1. Zhao D.: Carsharing: a sustainable and innovative personal transport solution with great potential and huge opportunities, Frost and Sullivan, 28 January. http://www.frost.com/sublib/display-marketinsight.do?id=190795176 (2010) (Accessed 23 April 2015).

2. Shaheen SA, Cohen AP. Innovative mobility carsharing outlook: carsharing market overview, trends, and analysis. Berkeley: Transportation Sustainability Research Center, University of California, Summer; 2015.

3. Shaheen, S.: Mobility and the sharing economy: past, present, and future keynote speech at first International Symposium on the Sharing Economy, Utrecht, Netherlands; 2015.

4. Economist. The future of the car: clean, safe and it drives itself, 20 April. www.economist.com/news/leaders/21576384-cars-havealready-changed-way-we-live-they-are-likely-do-so-again-cleansafe-and-it/print (2013). Accessed 24 April 2013.

5. Forrest A. and M. Konca.: Autonomous Cars and Society, Worcester Polytechnic Institute, 1 May. http://www.wpi.edu/Pubs/ E-project/Available/E-project-043007-205701/unrestricted/ IQPOVP06B1.pdf (2007) (Accessed 20 October 2013).

6. Broggi A., M. Bertozzi A. Fascioli and G. Conte. Automatic vehicle guidance: the experience of the ARGO autonomous vehicle, World Scientific. ISBN 981-02-3720-0, 250 pp. http://millemiglia. ce.unipr.it/ARGO/flyer.pdf (1999). Accessed 20 October 2013.

7. Dickmanns E. D.: Dynamic vision for perception and control of motion, Springer. ISBN 978-1-84628-638-4, 474 pp. http://www. springer.com/engineering/mechanical+engineering/book/978-1 84628-637-7 (2007). Accessed 20 October 2013.

8. EUREKA Network. Programme for a European traffic system with highest efficiency and unprecedented safety (PROMETHEUS), Brussels, Belgium. http://www.eurekanetwork.org/project/-/id/45 (2013). Accessed 20 October 2013.

9. DARPA (Defense Advanced Research Projects Agency) DARPA Urban Challenge, U.S. Department of Defense. http://archive. darpa.mil/grandchallenge/ (2007). Accessed 20 October 2013.

10. Carnegie Mellon University History of the Robotics Institute, The Robotics Institute, Carnegie Mellon University. http://www.ri.cmu. edu/ri_static_content.html?menu_id=247 (2013) (accessed 18 November 2013).

11. Sattinger I. J. and W. G. Dow. History of ERIM: the Environmental Research Institute of Michigan, 1946-1989, Environmental Research Institute of Michigan, 186 pp. http://books.google.com/ books/about/History of ERIM.html?id=CUniAAAAMAAJ \&focus=searchwithinvolume \&q=autonomous (1994) (accessed 18 November 2013).

12. SRI International. Unmanned robotics perception, http://www.sri. com/research-development/unmanned-robotics (2013). Accessed 18 November 2013

13. Google. Self-driving car test: Steve Mahan, Google Jobs, 15 April. http://www.google.com/about/jobs/lifeatgoogle/self-driving-cartest-steve-mahan.html. (2012) (2012) Accessed 15 August 2013.

14. Legal Examiner. Soon driverless cars may save us from distracted drivers. Cleveland, $\mathrm{OH}, 9$ October. http://cleveland.legalexaminer. com/automobileaccidents/soondriverlesscarsmaysaveusfrom distracteddrivers.aspx?googleid $=304796$

15. Undercoffler D. Nissan marches us toward driverless future. Los Angeles Times, 18 October. http://articles.latimes.com/2012/oct/ 18/business/la-fi-mo-nissan-auto-steer-20121018 (2012) (Accessed 20 November 2013).

16. Wall Street Journal. Who's behind the wheel? nobody. 24 September. http://online.wsj.com/article/SB10000872396390443 524904577651552635911824.html (2012). Accessed 9 August 2013.
17. BeforeItsNews Toyota and Audi to unveil driverless cars this week. 7 January. http://beforeitsnews.com/alternative/2013/01/videotoyota-and-audi-to-unveil-driverless-cars-this-week-2530696.html (2013). Accessed 20 November 2013.

18. Nissan News .Nissan announces unprecedented autonomous drive benchmarks, press release, 27 August. http://nissannews.com/enUS/nissan/usa/releases/nissan-announces-unprecedentedautonomous-drive-benchmarks (2013). Accessed 20 November 2013.

19. Anderson J. M., N. Kalra K. D. Stanley P. Sorensen C. Samaras O. A. Oluwatola: Autonomous vehicle technology: a guide for policymakers, RAND Corporation. http://www.rand.org/content/ dam/rand/pubs/research_reports/RR400/RR443-1/RAND_RR4431.pdf (2014).

20. BBC News. Driverless car bill is signed in California at Google headquarters, 26 September. http://www.bbc.co.uk/news/ technology-19726951 (2012). Accessed 20 November 2013.

21. Florida House of Representatives. House of Representatives Final Bill Analysis, Bill \# CS/HB 1207, 17 April. http://www. myfloridahouse.gov/Sections/Documents/loaddoc.aspx? FileName $=$ h 1207 z 1 . THSS.DOCX\&DocumentType $=$ Analysis\&BillNumber=1207\&Session=2012 (2012). Accessed 3 October 2013.

22. Slosson M: Google gets first self-driven car license in Nevada, Reuters, 8 May. http://www.reuters.com/article/2012/05/08/ukusa-nevada-google-idUSLNE84701320120508 (2012). Accessed 20 November 2013.

23. Council of the District of Columbia. Autonomous Vehicle Act of 2012, Law \# L19-0278, 23 April. http://dcclims1.dccouncil.us/ lims/legislation.aspx?LegNo=B19-0931 (2013). Accessed 21 November 2013.

24. NHTSA (National Highway Traffic Safety Administration). U.S. Department of Transportation Releases Policy on Automated Vehicle Development. NHTSA 14-13, May 30. http://www.nhtsa. gov/About+NHTSA/Press+Releases/ci.U.S.+Department + of + Transportation + Releases + Policy + on + Automated + Vehicle + Development.print (2013) accessed 26 October 2014.

25. IHS Automotive 2014. Emerging technologies: autonomous carsnot if, but when.

26. Folsom TC. Energy and autonomous urban land vehicles. IEEE Technol Soc Mag. 2012;31:28-38.

27. Templeton, B.: Where robot cars (Robocars) can really take us. http://www.templetons.com/brad/robocars/ (2013).

28. Brown A., J. Gonder and B. Repac: An analysis of possible energy impacts of autonomous vehicles. Road vehicle automation, G. Meyer, S. Beiker, eds. Springer. DOI: 10.1007/978-3-319-059907. http://assets.conferencespot.org/fileserver/file/64302/filename/ 14-5077.pdf Brown A., J. Gonder and B. Repac. (2014) An analysis of possible energy impacts of autonomous vehicles. Road vehicle automation, G. Meyer, S. Beiker, eds. Springer. DOI: 10. 1007/978-3-319-05990-7. http://assets.conferencespot.org/ fileserver/file/64302/filename/14-5077.pdf.

29. Morrow, W. R., J. B. Greenblatt, A. Sturges, S. Saxena, A. Gopal, D. Millstein, N. Shah, E. A. Gilmore. Key factors influencing autonomous vehicles' energy and environmental outcome. In: Road Vehicle Automation, G. Meyer, S. Beiker, eds. Springer; 2014 DOI: 10.1007/978-3-319-05990-7.

30. Troppe W. Energy implications of autonomous vehicles: imagining the possibilities, RMI Outlet (blog), Rocky Mountain Institute. http://blog.rmi.org/blog_2014_09_09_energy_implications_of autonomous_vehicles (2014).

31. Seward J. Mobileye NV Gains: Tesla Motors Inc. to use multiple suppliers for self-driving car. Benzinga, 8 September. http://www. benzinga.com/analyst-ratings/analyst-color/14/09/4833196/ mobileye-nv-gains-tesla-motors-inc-to-use-multiple-suppl\# (2014) accessed 13 Oct 2014. 
32. Navigant Research. Autonomous vehicles: self-driving vehicles, autonomous parking, and other advanced driver assistance systems: global market analysis and forecasts, 21 August. http://www. navigantresearch.com/research/autonomous-vehicles (2013). Accessed 26 September 2013.

33. Insurance Information Institute. Self-driving cars and insurance, September. http://www.iii.org/issue-update/self-driving-cars-andinsurance (2014). Accessed 17 September 2014.

34. KPMG The self-driving revolution: are we ready? http://www. kpmg.com/US/en/IssuesAndInsights/ArticlesPublications/ Documents/self-driving-cars-are-we-ready.pdf (2013). accessed 1 December 201.

35. Gomes L. Urban jungle a tough challenge for google's autonomous cars, MIT Technology Review, 24 July, http://www. technologyreview.com/news/529466/urban-jungle-a-toughchallenge-for-googles-autonomous-cars/ (2014). Accessed 2 October 2014.

36. Cabanatuan M. (2015) Northern California at center of driverless car development, San Francisco Chronicle, 21 March. http://www. sfchronicle.com/bayarea/article/Northern-California-at-center-ofdriverless-car-6150543.php.

37. Troppe W. Energy implications of autonomous vehicles: imagining the possibilities, RMI Outlet (blog), Rocky Mountain Institute. http://blog.rmi.org/blog_2014_09_09_energy_implications_of_ autonomous vehicles (2014).

38. Eno Center. Preparing a nation for autonomous vehicles: opportunities, barriers and policy recommendations, Eno Center for Transportation, October. https://www.enotrans.org/wp-content/ uploads/wpsc/downloadables/AV-paper.pdf (2013). Accessed 21 November 2013.

39. Chester MA, Horvath A, Madanat S. Parking infrastructure: energy, emissions, and automobile life-cycle environmental accounting, Environ Res Lett 2010;5:034001. doi:10.1088/1748-9326/5/3/ 034001.

40. NHTSA (National Highway Traffic Safety Administration). National motor vehicle crash causation survey: report to Congress. U.S. Department of Transportation, Report DOT HS 811 059, July. http://www-nrd.nhtsa.dot.gov/Pubs/811059.PDF (2008). Accessed 30 November 2014.

41. NYDMV (New York State Department of Motor Vehicles). Summary of motor vehicle crashes, 2012 Statewide Statistical Summary. http://dmv.ny.gov/statistic/2012nys.pdf (2012), accessed 4 October 2014.

42. Energy Information Administration. Annual energy outlook 2014, U.S. Department of Energy, April. http://www.eia.gov/forecasts/ aeo/ (2014). Accessed 27 September 2014.

43. National Academies of Science. Transitions to alternative vehicles and fuels. http://www.nap.edu/catalog.php?record_id=18264. (2013)

44. Greenblatt J. B., S. Saxena. Autonomous taxis could greatly reduce greenhouse gas emissions of U.S. light-duty vehicles. Nature Climate Change, 6 July. doi:10.1038/nclimate2685 (2015).
45. Dutzik T., J. Inglis and P. Baxandall. Millennials in motion: changing travel habits of young americans and the implications for public policy, U.S. PIRG Education Fund and Frontier Group, October. http://www.uspirg.org/sites/pirg/files/reports/Millennials\%20in\% 20Motion\%20USPIRG.pdf (2014). Accessed 9 June 2015.

46. Lu S. Vehicle survivability and travel mileage schedules, DOT HS 809 952, Technical Report, National Center for Statistics and Analysis, National Highway Traffic Safety Administration, January. http://www-nrd.nhtsa.dot.gov/Pubs/809952.pdf (2006), accessed 4 October 2014.

47. Shaheen SA, Cohen AP. Innovative mobility carsharing outlook: carsharing market overview, trends, and analysis. Berkeley: Transportation Sustainability Research Center, University of California; 2014. Summer 2014.

48. Chan ND, Shaheen SA. Ridesharing in North America: past, present and future. Transp Rev. 2012;32(1):93-112.

49. Christie, B. Gov. Doug Ducey signs bill overhauling ride-hailing rules, Seattle Post-Intelligencer, 9 April. http://m.seattlepi.com/ news/article/Gov-Doug-Ducey-signs-bill-overhauling-6190429. php(2015).

50. Martin EW, Shaheen SA. Greenhouse gas emissions impacts of carsharing in North America. IEEE Trans Intell Transp Syst. 2011;12(4):1074-86.

51. Shaheen S., Cohen A., and Chung M. (2009) North American Carsharing: a ten-year retrospective, transportation research record, no. 2110 , pp. $35-44$.

52. Shaheen S. and Chan N. (2015) Mobility and the sharing economy: impacts synopsis. Transportation Sustainability Research Center, University of California, Berkeley, Spring 2015.

53. Rayle et al. (2014) App-based, on-demand ride services: comparing taxi and ridesourcing trips and user characteristics in San Francisco. University of California Transportation Center, Working Paper, August 2014.

54. Fagnant DJ, Kockelman KM. The travel and environmental implications of shared autonomous vehicles, using agent-based model scenarios. Transport Res C: Emerg Technol. 2014;40:1-13.

55. Schaller Consulting. The New York City Taxicab Fact Book, March. http://www.schallerconsult.com/taxi/taxifb.pdf (2006).

56. Goodbody. Economic review of the small public service vehicle industry, goodbody economic consultants in association with Faber Maunsell and IMS Millward Brown. Published by the Commission for Taxi Regulation, Dublin, Ireland, March. http:// www.nationaltransport.ie/downloads/taxi-reg/economic-reviewspsv-industry.pdf (2009). Accessed 25 November 2014.

57. Gordon-Bloomfield, N. San Francisco: twice as many taxis burn half as much gas; Here's How. Green Car Reports, 15 February. http://www.greencarreports.com/news/1072985_san-franciscotwice-as-many-taxis-burn-half-as-much-gas-heres-how (2012). Accessed 30 November 2014.

58. Metro Taxi. Going green. Denver, CO. http://www.metrotaxidenver. com/going-green/ (2013).

59. Federal Highway Administration (2011). National Household Travel Survey 2009. U.S. Department of Transportation. 